\title{
TITIK SEBAGAI DASAR PENCIPTAAN KARYA SENI
}

\author{
Hanny Wijaya \\ Jurusan Desain Komunikasi Visual, Fakultas Komunikasi dan Multimedia, \\ Bina Nusantara University, Jln. K.H. Syahdan No. 9, Palmerah, Jakarta Barat 11480 \\ hwijaya@binus.edu
}

\begin{abstract}
Basic element of subject is point / dot. Line, shape, form (two-dimensional and three-dimensional), and other structures (geometrically or ornamentally) are formed by a group or more points. The variety of size and composition of point will illustrate the characteristic of that point. Interesting composition will create a great artwork. Despite of variety of the structure, the technical process of colour dots had been developed for a long time. During the development of Impressionism art, some artists had tried to apply the colour dots as a new technique, which called Pointillism. Georges Seurat was a pioneerof this technique development. Pointillism was well known as Divisionism or Chromoluminarism at that moment. This technique was using an additive method that combined basic pigment colours of red, green and blue to produce optical vibration in the painting, therefore the viewers would be able to reach the maximum luminosity in their vision. The existence of this technique had proved that science and art were able to support each other. The combination of logic and aesthetic were able to create many extraordinary artworks.
\end{abstract}

Keywords: point, composition, art, application, pointillism

\begin{abstract}
ABSTRAK
Elemen dasar dari sebuah subyek adalah titik.Garis, bidang, bentuk (dua-dimensi dan tiga-dimensi), serta bentuk lainnya (geometris atau ornamental) semua terbentuk dari kumpulan titik.Permainan ukuran dan komposisi titik dapat menunjukkan karakter dari titik tersebut.Dengan penyusunan komposisi yang menarik, kumpulan titik bisa menjadi sebuah karya seni yang menarik.Selain permainan bentuk dan komposisi, pengolahan titik-titik warna sudah berkembang sejak lama. Pada masa pergerakan seni Impresionisme, beberapa seniman sudah mencoba untuk mengaplikasikan titik-titik warna sebagai sebuah teknik baru yang disebut dengan Pointilisme. Georges Seurat adalah seniman yang menjadi pelopor pengembangan teknik ini. Teknik Pointilisme sering dikenal dengan sebutan Divisionisme atau Chromoluminarism pada masanya.Teknik ini menggunakan metode additif yang mengkombinasikan pigmen dasar warna merah, hijau dan biru untuk menghasilkan vibrasi optikal pada lukisan, sehingga para pengamat lukisan dapat mencapai tingkat luminosity yang maksimal pada mata.Keberadaan teknik Pointilisme ini telah membuktikan bahwa ilmu pengetahuan dan seni dapat saling mendukung.Perpaduan logika dan estetika dapat menciptakan karya seni yang luar biasa.
\end{abstract}

Kata kunci: titik, komposisi, seni, aplikasi, pointilisme 


\section{PENDAHULUAN}

Pada saat kita kanak-kanak, kita diajarkan teknik dasar untuk menggambar sederhana yang nantinya akan menjadi bekal untuk melatih kepekaan estetika. Oleh para guru, kita diajarkan berbagai bentuk sederhana. Menggambar berbagai bentuk yang mudah kita ingat, umumnya kita diajarkan untuk mengenal berbagai bentuk geometris, seperti lingkaran, segitiga, persegi panjang, segi empat, dan lain sebagainya. Bentuk-bentuk geometris tersebut yang nantinya akan menjadi pola dasar kita menggambar sebuah obyek, misalnya lingkaran untuk menggambar bentuk matahari, segitiga mewakili bentuk gunung, persegi panjang untuk menggambar mobil, dan bentuk-bentuk lainnya. Seiring dengan waktu, apabila kita terus berlatih, maka gambar-gambar tersebut akan semakin sempurna bentuknya dan menyerupai bentuk obyek aslinya.Dari sini dapat kita lihat bahwa sebuah bidang sederhana, merupakan pola dasar dari terwujudnya sebuah subyek yang menjadi inspirasi penciptaan karya seni.

Namun, apabila kita bergerak mundur dan menelusuri inspirasi penciptaan karya seni, maka kita akan mendapatkan sebuah perkembangan yang menarik. Subyek sebagai inspirasi penciptaan karya seni yang lebih detail dan rumit, umumnya merupakan sebuah bentuk, baik itu dua-dimensi maupun tiga-dimensi. Bentuk dapat tercipta melalui bidang yang ditekuk atau bidang yang diputar. Setiap permukaan suatu benda mempunyai bentuk (form). Bentuk yang berupa tiga-dimensi terbagi menjadi 2 jenis, yaitu bentuk terbuka dan bentuk tertutup, yang sering juga disebut dengan ruang. Kemudian, bila kita telusuri lagi ke belakang sebuah ruang terbentuk dari kumpulan berbagai bidang (lingkaran, segitiga, persegi panjang, dan lain sebagainya). Bidang memiliki bentuk yang lebih sederhana dari pada ruang, karena bidang tidak memiliki volume atau isi. Bidang hanya memiliki luas (hasil penghitungan perkalian dari panjang dan lebar), karena bidang bersifat dua-dimensi.

Kita mundur selangkah lagi, maka kita temukan bahwa bidang merupakan kumpulan dari beberapa garis.Garis dapat menunjukkan arah dan gerak, serta memiliki karakter.Garis lurus memiliki karakter yang stabil dan menunjukkan arah yang jelas.Garis lengkung memiliki sifat yang feminin, lembut, selain itu garis lengkung juga menunjukkan adanya pergerakan yang dinamis dan energik. Sedangkan garis patah-patah (zig-zag) memiliki sifat yang masculine, kaku dan tegas. Garis patahpatah juga menunjukkan pergerakan yang kaku. Kemudian kita kembali ke asal muasal terciptanya garis, yaitu titik yang merupakan permulaan dari terciptanya semua elemen seni yang kita bahas sebelumnya (bentuk, bidang dan garis). Berikutakan dibahas lebih jauh mengenai latar belakang, karakter dan pengaplikasian titik dan penggunaannya di dalam penciptaan suatu karya seni. Selain itu, kita akan membahas mengenai salah satu pergerakan seni rupa barat yang memanfaatkan titik-titik warna sebagai ciri khasnya, pergerakan seni ini ada di dalam periode seni Impresionisme dan dikenal dengan Pointilisme.

\section{METODE PENELITIAN}

Penulisan disusun menggunakan pendekatan studi literatur, yang berdasarkan pada sumber informasi tercetak dan elektronik.Kemudian penulis mengembangkan data-data dan informasi yang ada dari sumber informasi tersebut dengan menambahkan informasi lanjut yang berdasarkan pada pengamatan, hipotesa dan pengembangan ide dari materi yang ada. 


\section{HASIL DAN PEMBAHASAN}

\section{Karakter dan Aplikasi Titik}

Titik merupakan elemen terkecil dari suatu bentuk.Karakter dari titik dapat dilihat berdasarkan dari ukuran, yaitu besar kecilnya suatu titik.Titik dengan ukuran yang besar memberikan kesan lebih berat atau kuat daripada titik dengan ukuran kecil.Permainan ukuran besar atau kecil titik memberikan kesan tertentu sesuai dengan keinginan dari seniman atau desainernya, sehingga dapat menyampaikan ide atau pesan dari karya seni yang diciptakannya.

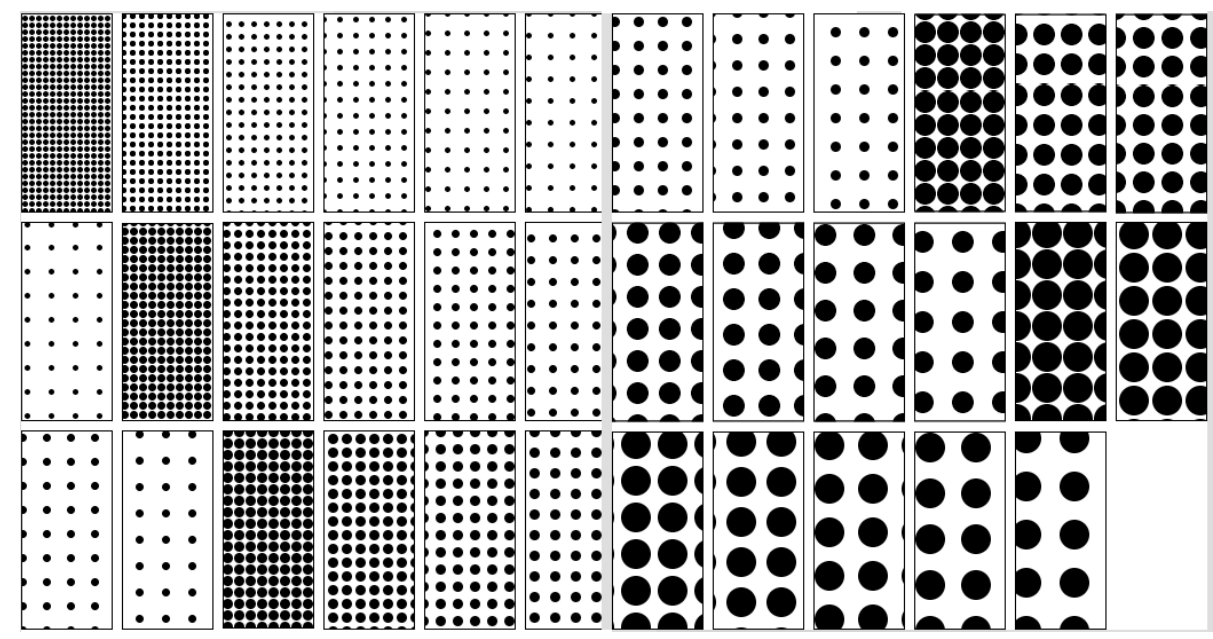

Gambar 1 Berbagai ukuran titik

Garis merupakan kumpulan dari titik dengan jarak yang rapat dan sangat berdekatan. Namun titik dalam jumlah banyak dengan posisi yang tidak beraturan atau menyebar dapat membentuk sebuah bidang atau bentuk baru (dua-dimensi) dengan karakter yang unik.

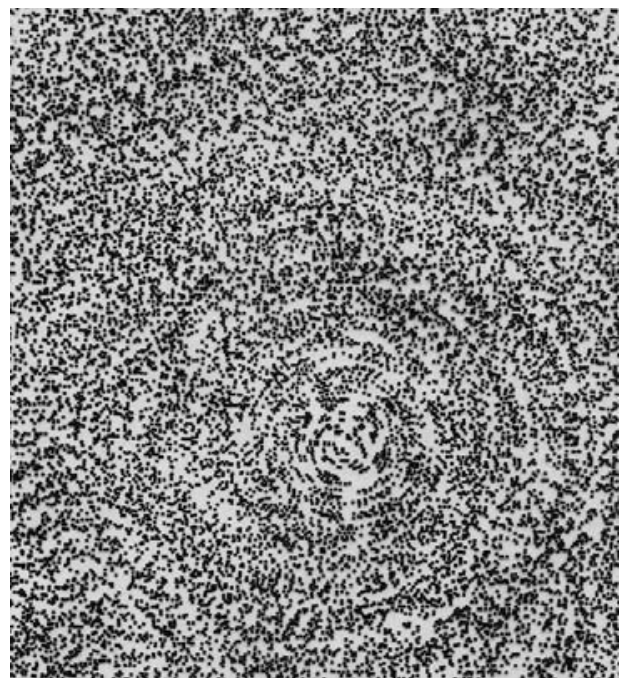

Gambar 2 Desain yang berasal dari sebaran titik 
Titik sebagai salah satu elemen yang penting di dalam pemanfaatan dan pengaplikasian-nya pada bidang seni, baik itu seni terapan (applied art) maupun seni murni (fine art).Di dalam seni terapan, titik banyak dimanfaatkan pada desain.Salah satu pengaplikasian titik di dalam desain adalah aplikasi titik sebagai pola (pattern). Pola (pattern) berasal dari bahasa Perancis yaitu patron, adalah kumpulan dari elemen yang berulang dan merupakan satu kesatuan.Elemen-elemen tersebut tertata di dalam sebuah susunan yang rapi dan teratur.Pola sering dijadikan sebagaitemplate atau model yang bisa digunakan secara umum untuk menciptakan sesuatu.Pola biasanya selalu berupa pengulangan, terkadang ukuran dan bentuk yang sama, namun bisa juga pengulangan ukuran dan bentuk yang berbeda menjadi pola tertentu yang unik. Pola secara umum merupakan hasil pemikiran yang diwujudkan dalam bentuk dua-dimensi.

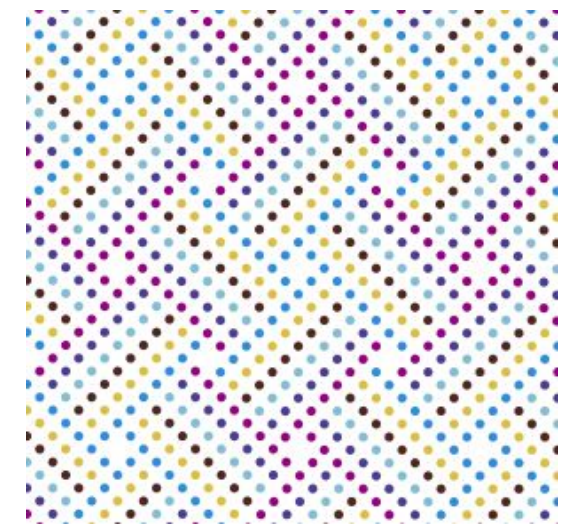

Gambar 3 Pola Pengulangan Titik (ukuran sama)

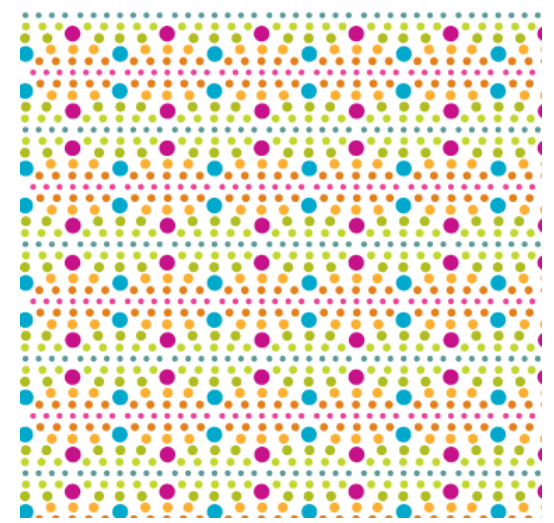

Gambar 4 Pola Pengulangan Titik (ukuran beda)

Berdasarkan contoh yang ada pada kedua gambar tersebut, dapat dilihat bahwa susunan dan ukuran dari titik memberikan kesan dan karakter yang berbeda satu sama lainnya. Pada contoh gambar 3, pola diperoleh berdasarkan susunan titik dengan ukuran yang sama. Titik disusun secara patahpatah (zig-zag) sehingga memberi kesan gerak (movement). Ukuran yang sama memberi kesan rapi dan teratur. Sedangkan pada contoh gambar 4, pola pengulangan menggunakan beberapa variasi ukuran titik yang berbeda.Pola disusun berulang dengan rapi, namun permainan ukuran (size) dari titik memberikan variasi dan karakter desain yang unik.

Permainan ukuran dan susunan dari titik tidak selalu menjadi pola pada akhirnya. Ciri khas dari pola adalah susunan yang teratur dan berulang-ulang. Namun seorang seniman atau desainer bisa memanfaatkan susunan titik untuk membuat sebuah bentuk dua-dimensi yang baru, hasil eksperimental tersebut menjadi sebuah karya seni.

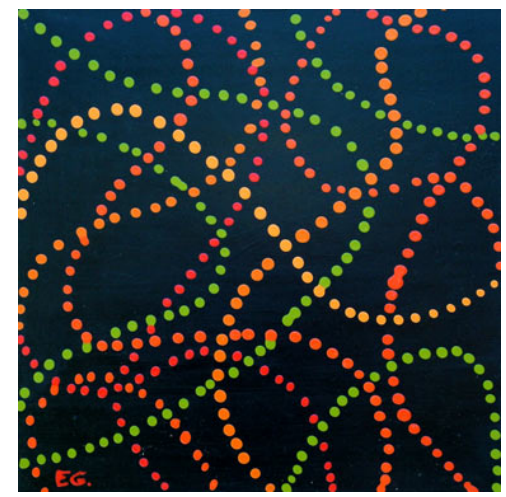

Gambar 5 Permainan Susunan Titik 
Permainan bentuk dan ukuran juga terkadang memberi kesan dimensi yang berbeda. Hasil karya dua-dimensi bisa memberi kesan tiga-dimensi bila seniman atau desainer menciptakan karya seni dengan memanfaatkan posisi dan ukuran titik tersebut sebagai subyek seni. Titik dibuat sebagai subyek atau bentuk baru di dalam perancangan karya seni.

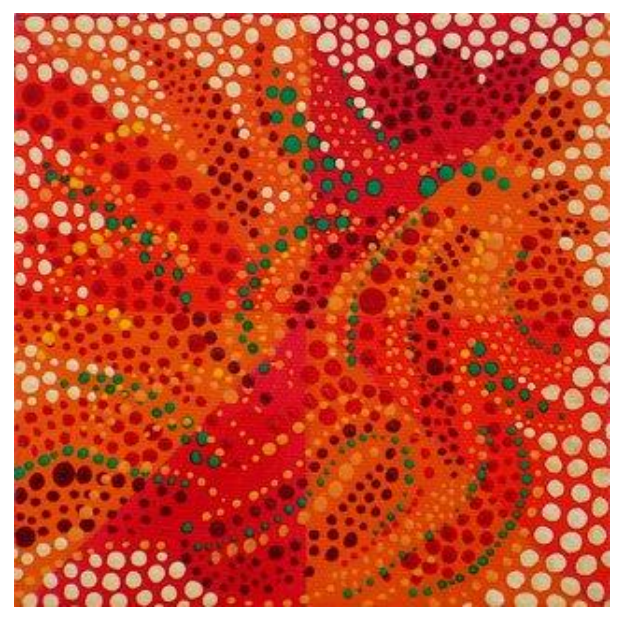

Gambar 6 Aplikasi Desain Dua-dimensi

\section{Pointilisme}

Pemanfaatan titik sebagai elemen dasar penciptaan karya seni sudah berkembang sejak berabad-abad dan terus berkembang hingga saat ini. Salah satu penggunaan titik sebagai salah satu ciri khas karya seni yaitu pada saat pergerakan karya seni Impresionisme, pergerakan tersebut dikenal dengan nama Pointilisme yang dipelopori oleh seniman Perancis, Georges Seurat.

Pointilisme merupakan sebuah teknik melukis dengan memanfaatkan titik-titik kecil dari warna asli yang diaplikasikan menjadi sebuah pola untuk membentuk sebuah image. Pada awalnya Georges Seurat mengembangkan teknik ini pada tahun 1886 sebagai cabang dari gerakan Impresionisme, namun karena keunikan dari teknik melukis ini, gerakan ini menjadi sebuah gaya yang terkenal sendiri pada periode keemasannya.

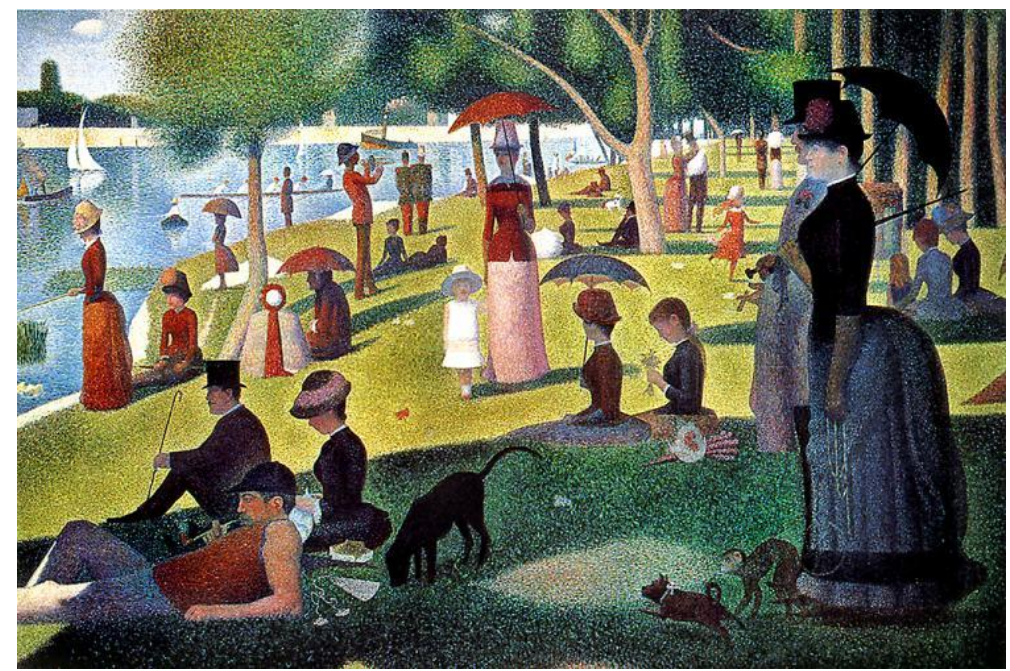

Gambar 7 Georges Seurat, Sunday Afternoon on the Island of La Grand Jatte, 1884-86, Oil on Canvas 
Teknik Pointilisme bergantung pada kemampuan perseptif dari mata dan pemikiran dari pengamat karya seni untuk memadukan titik-titik warna tersebut. Teknik ini membutuhkan kesabaran, menggunakan metode khusus dan waktu yang cukup panjang untuk pengerjaannya. Seurat mencoba untuk menciptakan teknik baru untuk menyempurnakan karya-karya pelukis akademik periode Impresionis sebelumnya yang bersifat lebih bebas, tanpa aturan dan menggunakan permainan warna yang cerah. Ia mencoba untuk menyempurnakan gaya Impresionisme dengan memaksakan logika dan disiplin di dalam penciptaan karya seni tersebut. Seurat menyebut teknik tersebut 'chromoluminarism', namun teknik ini pada akhirnya lebih dikenaldengan 'Divisionisme' (atau Pointilisme).

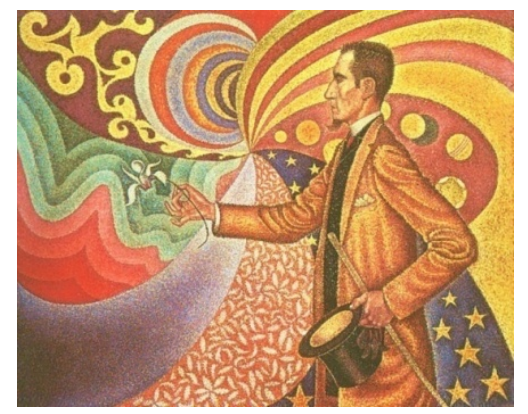

Gambar 8 Paul Signac, Portrait of Félix Fénéon, 1890

Ciri khas dari pemanfaatan titik-titik warna pada lukisan Pointilisme adalah warna kontras yang kuat daripada metode biasa yang memanfaatkan perpaduan atau pencampuran dari pigmen warna pada palet pada saat melukis. Pointilisme menggunakan warna-warna asli tanpa dicampur untuk mendapatkan suatu warna tertentu. Teknik pewarnaan ini bersifat analog untuk pencetakan empat warna - CMYK (Cyan, Magenta, Yellow dan Black).

Pointilisme menggunakan teori warna untuk mencapai photorealistic image yang mengenai retina mata dari pengamat lukisan tersebut. Warna lebih terang dan kontras yang dihasilkan pada titiktitik warna pointilisme menghasilkan perpaduan warna yang menggunakan sapuan kuas dan warna dasar dari cat minyak akan menciptakan tekstur khusus pada lukisan Pointilisme tersebut. Pada dasarnya bahan cat atau material lain bisa dimanfaatkan untuk melakukan teknik Pointilisme, namun cat minyak biasanya lebih sering dijadikan pilihan karena ketebalan dan kekentalannya mempermudah penggunaan teknik ini.

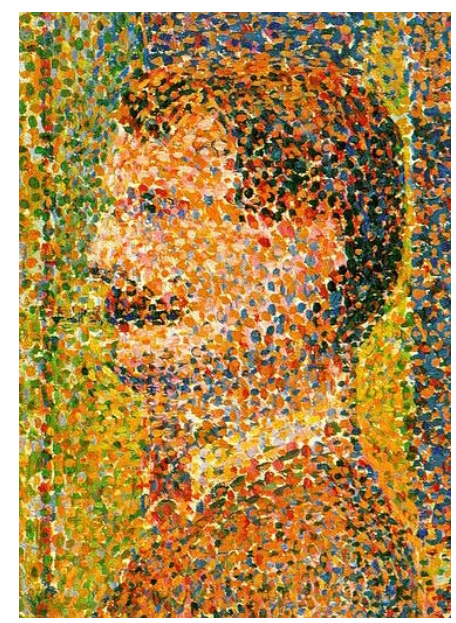

Gambar 9 Georges Seurat, Parade de Cirque, 1889, Oil on Canvas 


\section{Divisionisme}

Merupakan dasar dari munculnya teknik Pointilisme, Divisionisme lebih mengutamakan pada pemisahan warna pada titik-titik yang bersifat individu atau masing-masing, dengan pemanfaatan teknik ini, warna tidak dicampur secara manual di atas palet cat, namun setiap titik warna merupakan warna asli, kemudian ketika dilihat secara keseluruhan akan menghasilkan efek optikal pada mata, sehingga warna seakan-akan bercampur secara selaras.

Sebenarnya Divisionisme sering dianggap sama dengan Pointilisme, namun bila dipelajari lebih jauh maka ditemukan bahwa Divisionisme lebih bersifat teknikal dengan metode yang beragam. Selain itu Divisionisme lebih memfokuskan teknik dan metodenya dengan berdasarkan pada teori warna, dimana Pointilisme lebih fokus pada gaya penyapuan kuas yang lebih spesifik pada saat diaplikasikan pada lukisan. Pemanfaatan teknik ini dapat dilihat pada hasil karya lukisan Seurat, Signac dan Cross.

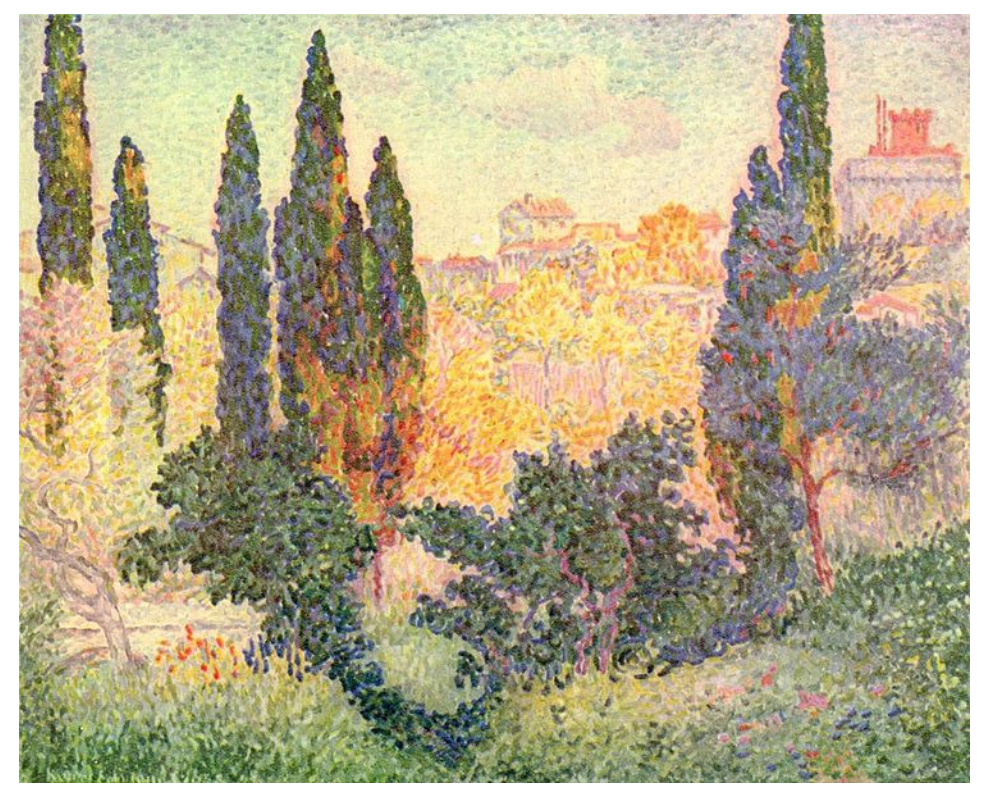

Gambar 10 Henry Edmund Cross,Cypresses at Cagnes, 1900

Dengan memanfaatkan mata dari pengamat lukisan yang menggabungkan warna-warna secara optikal dengan menggabungkan pigmen warna secara fisik, teknik Divisionis percaya bahwa mereka dapat mencapai tingkat luminosity yang maksimal. Pointilisme menggunakan teknik pewarnaan dasar dari teknik Divisionisme, namun Pointilisme lebih spesifik pada pemanfaatan titik-titik warna cat dan tidak secara khusus memfokuskan diri pada separasi warna.

Divisionisme berkembang pada teknik melukis abad ke-19, yaitu ketika para seniman menemukan teori sains untuk penglihatan dan menjadi pemicu dasar perkembangan gerakan Impresionisme yang pada saat itu sudah berkembang dengan pesat. Teori sains dan peraturan mengenai kontras warna yang dapat menjadi panduan bagi para pendukung gerakan divisionis untuk mengembangkan gerakan Impresionisme menjadi lebih kontras dari gerakan Neo-Impresionisme, yang memiliki karakteristik lebih khusus pada insting dan intuisi seniman. 


\section{Teori Warna Chromoluminarism}

Teknik pewarnaan Divisionisme (Chromoluminarism) menggunakan teori warna dan penglihatan yang berupa perpaduan optikalakan menghasilkan cahaya yang lebih terang dan warna alami daripada proses tradisional yang memadukan warna pigmen secara manual.

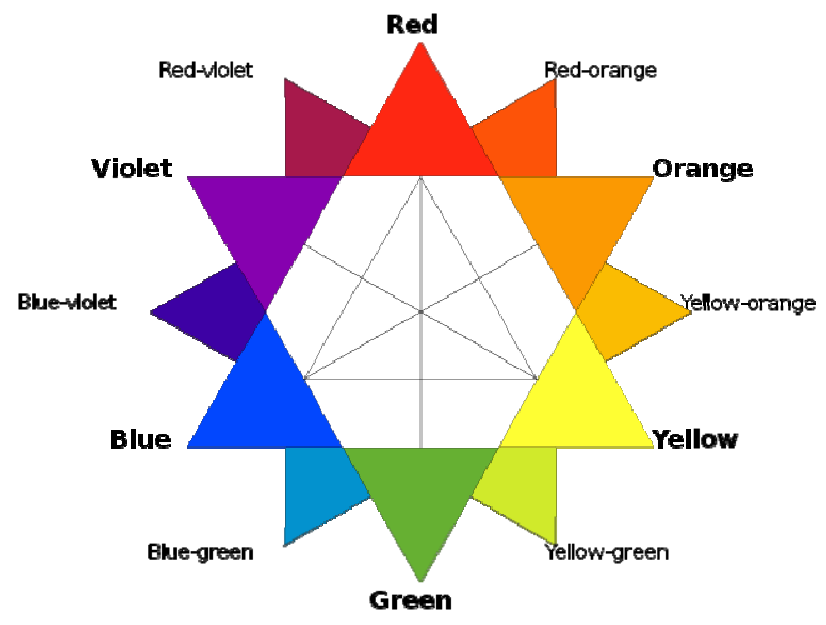

Gambar 11 Teori Warna - Bintang Warna

Memadukan warna pigmen secara fisikal disebut dengan proses substraktif, dengan menggunakan warna merah, kuning dan biru menjadi warna primer. Di sisi lain, bila pencahayaan warna dipadukan, maka akan menghasilkan paduan additif, sebuah proses yang menggunakan warna merah, hijau dan biru sebagai warna primernya. Perpaduan optikal yang menjadi karakteristik divisionisme, yaitu proses pencampuran warna dengan perbandingan kontras pigmen, berbeda dengan pencampuran additif maupun substraktif, walaupun mengkombinasikan warna pada perpaduan optikal menggunakan cara yang sama dengan perpaduan additif (penggunaan warna primer yang sama).

Pada lukisan yang berjudul Bathers at Asniéres (gambar 12) yang merupakan lukisan awal yang dibuat pada tahun 1884, Seurat mencoba untuk melakukan terobosan awal sebelum akhirnya teknik lukisannya menjadi terkenal (Pointilisme).

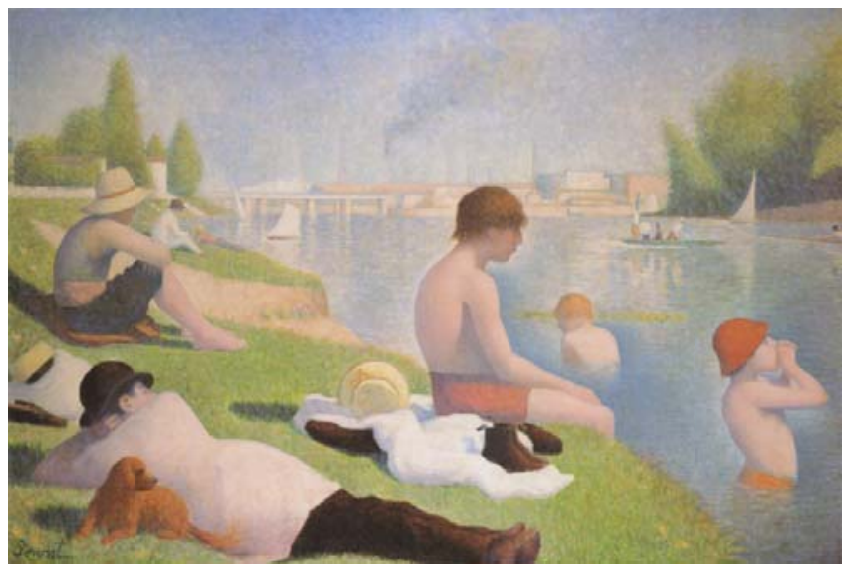

Gambar 12 Georges Seurat, Bathers at Asniéres, 1884, Oil on Canvas 
Seurat memilih pemandangan di tepi sungai dengan masyarakat sekitar yang sedang berenang dan berjemur sebagai obyek lukisannya. Seurat sempat memperbaiki dan mengerjakan ulang lukisan pada kanvasnya, ia mencoba untuk mengaplikasikan titik-titik kecil dari warna biru, jingga dan kuning pada lukisannya, terutama pada topi anak yang ada di air. Lukisan tersebut merupakan langkah awal bagi Seurat sebelum ia menghasilkan masterpiece yang terkenal, yaitu lukisan Sunday Afternoon on the Island of La Grande Jatte.

Lukisan karya Seurat sebenarnya tidak terlalu mencapai perpaduan optikal yang sebenarnya; bagi Seurat, teori warna tersebut lebih berguna untuk menimbulkan kesan vibrasi warna untuk pengamat lukisan tersebut, dimana kontras warna-warna yang diletakkan berdekatan satu sama lainnya akan meningkatkan hubungan di antara beberapa warna tersebut ketika menjaga kestabilan identitas warna masing-masing. Pada gambar 13 berikut, ditunjukkan lebih mendetail mengenai penggunaan warna dengan memanfaatkan vibrasi warna untuk mendapatkan efek optikal pada warna lukisan yang ingin dicapai, yaitu dengan menggunakan titik-titik warna primer pada lukisan tersebut.

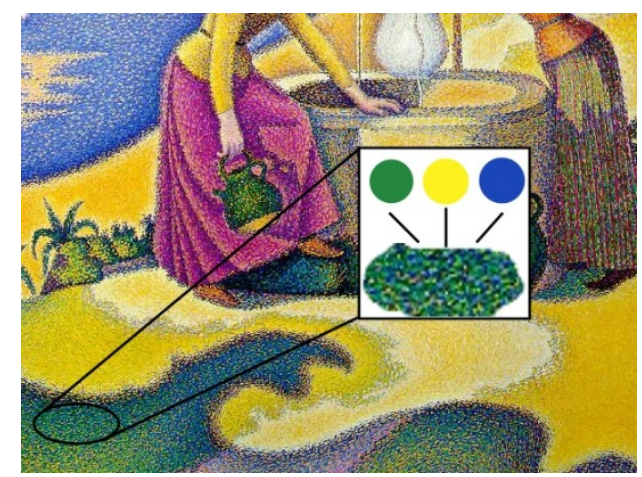

Gambar 13 Contoh Detail Warna dari Lukisan Paul Signac, Femme au Puits, 1892

Perkembangan gaya lukisan Pointilisme juga mempengaruhi beberapa seniman besar yang ada pada masa transisi antara masa Impresionisme dengan Neo-Impresionisme. Salah satu contohnya adalah pelukis besar Vincent van Gogh. Ia mengembangkan teknik Pointilisme pada lukisan-lukisan awalnya, dan terus berkembang sesuai dengan pergerakan seni di Eropa pada masa tersebut. Salah satu lukisan awalnya yang menggunakan teknik Pointilisme (Divisionisme) adalah lukisan Self Portrait yang dihasilkannya pada tahun 1887.

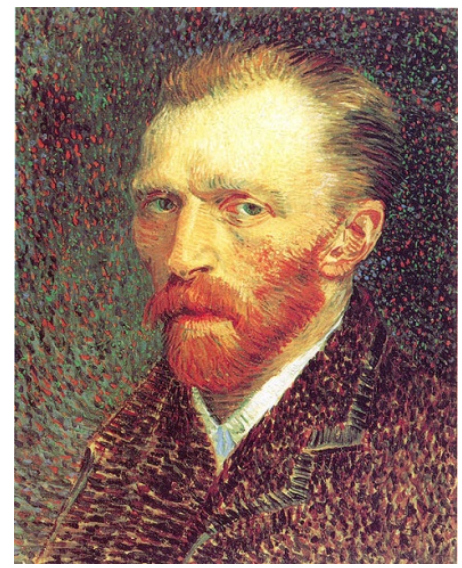

Gambar 14 Vincent van Gogh, Self Portrait, 1887, Oil on Canvas 


\section{SIMPULAN}

Berdasarkan semua pendapat yang ada, maka dapat dilihat bahwa walaupun titik merupakan sebuah unsur yang terkecil, hanya sebuah elemen dasar, namun titik merupakan asal mula dari penciptaan karya seni. Penciptaan garis, bidang, bentuk dan ruang merupakan inspirasi dasar atau subyek awal bagi penciptaan karya seni lainnya. Permainan ukuran, komposisi dan peletakan titik dapat menghasilkan sebuah karya seni baru yang unik.Ilmu pengetahuan, sains dan seni bisa dipadukan dan bermanfaat untuk menciptakan sebuah teknik baru didalam perancangan karya seni. Permainan indera penglihatan yang dipadukan dengan ilmu pengetahuan, akan menghasilkan sebuah penglihatan optikal. Sehingga dapat disimpulkan bahwa sebuah bentuk dasar bisa menjadi sebuah subyek utama untuk penciptaan sebuah masterpiece. Sebagai contohnya adalah titik, apabila disusun dan dikomposisikan dengan benar, dapat menghasilkan sebuah karya seni yang luar biasa. Selain itu, dapat pula disimpulkan bahwa ilmu pengetahuan dan sains tidak selalu bertentangan dengan seni dan estetika. Apabila dimanfaatkan dengan baik, maka ilmu pengetahuan bisa menjadi pendukung untuk menciptakan sebuah teknik baru untuk menghasilkan karya seni yang indah dan unik.

\section{DAFTAR PUSTAKA}

A Cassel Book. (2008). Defining moments in Art.USA and Canada: Sterling Publishing Co., Inc.

Engelmann, I. J. (2007). Impressionism: 50 Paintings you should know. New York: Prestel Publishing.

Honour, H., \& Fleming, J. (2009). A world history of Art: revised seventh edition. London: Laurence King Publishing Ltd.

Ocvirk, O. G., Stinson, R. E., Wigg, P. R., Bone, R. O., \& Cayton, D. L. (2006). Art fundamentals: theory and practice. New York: McGraw-Hill Companies. 